\title{
Synthesis and characterization of ester derivatives of stilbene derived from acid derivative (of $p$-chloro phenyl acetic acid, substitute benzaldehyde, triethyl amine) with methanol and sulphuric acid
}

\author{
Paresh S. More*, Santosh G. Singh \\ Department of Chemistry, KET'S V.G Vaze College, Mulund(E), Mumbai - 400081, \\ Maharashtra, India \\ *E-mail address: paresh.m34@gmail.com
}

\begin{abstract}
Two stilbene derivatives have been synthesized in two step process. First step involved synthesis of acid derivative from p- chloro phenyl acetic acid, substituted benzaldehyde and triethyl amine, where as the second step involved synthesis of substituted stilbene derivatives (enoate or esters) through very simple route. These derivatives were characterized by various spectral techniques and were screened for their antimicrobial activities.
\end{abstract}

Keywords: Stilbenes; phenylacetic acid; synthesis; antimicrobial activity

\section{INTRODUCTION}

Stibene derivatives have attracted much attention due to their diverse biological activities, including antimicrobial and insecticidal effects, vasodilation action as well as insect baculovirus synergists [1-6]. Stilbene derivatives such as diethylstilbestrol (DES) euvestin, 4,4'-diaminostilbene and pinosylvin, have a variety of biological action, including hormonal, hypocholesterolic, sympathomimetic, antifungal, antiallergic, antibacterial, antimalarial and anticancer activities [7-10]. Resveratrol (4,3,5- trihydroxy stilbene) which is present in grapes, peanuts, pine apple and also grape product such as wine, exert potent anti- oxidant and anti inflammatory activities [11-13]. In continuation of our earlier research [14] on the similar topic in this paper we are reporting synthesis of ester analogues of stilbene. They were characterized by various spectral techniques such as ${ }^{1} \mathrm{H}-\mathrm{NMR}$, IR and Elemental analysis.

\section{EXPERIMENTAL PROCEDURE}

${ }^{1} \mathrm{H}-\mathrm{NMR}$ spectra were recorded on a Brukner Act $300(300 \mathrm{Mz})$ spectrophotometer. Elemental analysis were carried out at Department Of Chemistry, University Of Mumbai. Infrared spectra were recorded on Perkin Elmer FTIR-4200 spectrometer at V.G.Vaze College. All the melting points were uncorrected. Temperature was recorded in ${ }^{0} \mathrm{C}$. 
Procedure for the preparation of ester derivative of stilbene fromcarboxylic acid derivatives, derived (from benzaldehyde, p-chloro phenyl acetic acid,triethyl amine) with methyl alcohol and concentrated sulphuric acid.

\subsection{Preparation of carboxylic acidderivative}

A mixture of p- chloro phenyl acetic acid, substituted benzaldehyde (equimolar) was refluxed along with trimethylamine for $24 \mathrm{hrs}$ and the hot solution was break in sodium carbonate solution and left for $24 \mathrm{hrs}$. The mixture was extracted with ether. The aqueous solution was acidified with dilute $\mathrm{HCl}$ and the precipitate was filtered, dried in vacuum desiccator and used without further purification.

\subsection{Preparation of substituted stilbene derivatives (esters or enoate) from carboxylic acid derivative}

Carboxylic acid derivative was dissolved in methanol and acidified with $2 \mathrm{ml}$ conc. $\mathrm{H}_{2} \mathrm{SO}_{4}$. The mixture was refluxed for 8 hours and the solution was concentrated to one third of the volume by heating on water bath. This solution was break into ice. The product obtained was treated with $100 \mathrm{ml}$ of petroleum ether and washed with dilute $\mathrm{NaOH}$ as the solution is acidic . Further the product obtained was treated with distilled water. Ether was evaporated . Product obtained was filtered and dried in vacuum dessicator.

\section{RESULT AND DISCUSSION}

Synthesized compounds PM-001 to PM-003, their theoretical and practical data of elemental analysis are in very good agreement as shown in the Table 1, which confirms formation of carboxylic acid derivative and its ester derivatives of stilbene.

IR Spectral data $\left(\mathrm{cm}^{-1}\right),{ }_{1}^{1} \mathrm{H}$ NMR Spectral data $(\delta \mathrm{ppm})$ and antibacterial activity of the carboxylic acid derivative and its ester derivatives of stilbene is shown in the Table 2 and 3 .

Table 1. Physical and analytical data of the carboxylic acid derivative and ester derivative of stilbene.

\begin{tabular}{|c|c|c|c|c|c|c|c|c|c|}
\hline Compound & $\begin{array}{c}\text { Mol. } \\
\text { Formula }\end{array}$ & $\begin{array}{c}\text { Mol. } \\
\text { Wt. }\end{array}$ & $\begin{array}{c}\text { \% } \\
\text { Yield }\end{array}$ & $\begin{array}{c}\text { Melting } \\
\text { Point }\end{array}$ & Colour & Carbon & Hydrogen & Nitrogen & Chlorine \\
\hline $\mathrm{PM}-001$ & $\mathrm{C}_{15} \mathrm{H}_{11} \mathrm{O}_{2} \mathrm{Cl}$ & 259 & 70 & $170^{0} \mathrm{C}$ & White & $\begin{array}{c}69.49 \\
(69.00)\end{array}$ & $\begin{array}{c}4.24 \\
(3.95)\end{array}$ & $\begin{array}{c}13.70 \\
(13.25)\end{array}$ \\
\hline $\mathrm{PM}-002$ & $\mathrm{C}_{16} \mathrm{H}_{13} \mathrm{O}_{2} \mathrm{Cl}$ & 273 & 75 & $72^{0} \mathrm{C}$ & White & $\begin{array}{c}70.32 \\
(69.68)\end{array}$ & $\begin{array}{c}4.76 \\
(4.15)\end{array}$ & - & 13.00 \\
$(13.45)$
\end{tabular}


Table 2. IR spectral data $\left(\mathrm{cm}^{-1}\right)$ and ${ }^{1} \mathrm{H}-\mathrm{NMR}$ spectral data of the carboxylic acid derivative and ester derivatives of stilbene.

\begin{tabular}{|c|c|c|c|c|c|c|c|c|c|}
\hline \multirow[b]{2}{*}{ Compound } & \multicolumn{5}{|c|}{ IR Spectral Data $\left(\mathrm{cm}^{-1}\right)$} & \multicolumn{4}{|c|}{${ }^{1}$ H-NMR Chemical Shift ( $\delta$ ppm) } \\
\hline & $\begin{array}{c}v_{(\mathrm{C}-\mathrm{H})} \\
\text { aromatic }\end{array}$ & $\begin{array}{c}v_{(\mathrm{C}-\mathrm{H})} \\
\text { aliphatic }\end{array}$ & $\begin{array}{c}\mathbf{v} \\
(\mathrm{C}-\mathrm{O})\end{array}$ & $\mathbf{v}_{(\mathrm{C}=\mathrm{C})}$ & $\begin{array}{c}\mathbf{v} \\
(\mathrm{C}-\mathrm{C})\end{array}$ & ${ }^{1} \mathbf{H}_{\mathrm{COOH}}$ & $\begin{array}{l}\text { 1H- } \\
\text { CH }\end{array}$ & $\begin{array}{l}\text { 9H- } \\
\text { ArH }\end{array}$ & $\begin{array}{c}3 \mathrm{H}- \\
\mathbf{O C H}_{3} \\
\end{array}$ \\
\hline $\begin{array}{c}\mathrm{C}_{15} \mathrm{H}_{11} \mathrm{O}_{2} \mathrm{Cl} \\
(\mathrm{PM}-001)\end{array}$ & 3035 & 2925 & 1680 & 1620 & 550 & 10.25 & 7.38 & $\begin{array}{l}7.31- \\
6.54\end{array}$ & - \\
\hline $\begin{array}{c}\mathrm{C}_{16} \mathrm{H}_{13} \mathrm{O}_{2} \mathrm{Cl} \\
(\mathrm{PM}-002)\end{array}$ & 3085 & 2940 & 1710 & 1625 & 560 & - & 7.69 & $\begin{array}{l}7.00- \\
6.973\end{array}$ & 3.36 \\
\hline $\begin{array}{c}\mathrm{C}_{16} \mathrm{H}_{12} \mathrm{O}_{2} \mathrm{Cl}_{2} \\
(\mathrm{PM}-003)\end{array}$ & 3090 & 2840 & 1710 & 1626 & 560 & - & 8.20 & $\begin{array}{l}7.12- \\
6.80\end{array}$ & 3.80 \\
\hline
\end{tabular}

Table 3. Antibacterial activity of carboxylicacid derivative and its ester derivatives of stilbene.

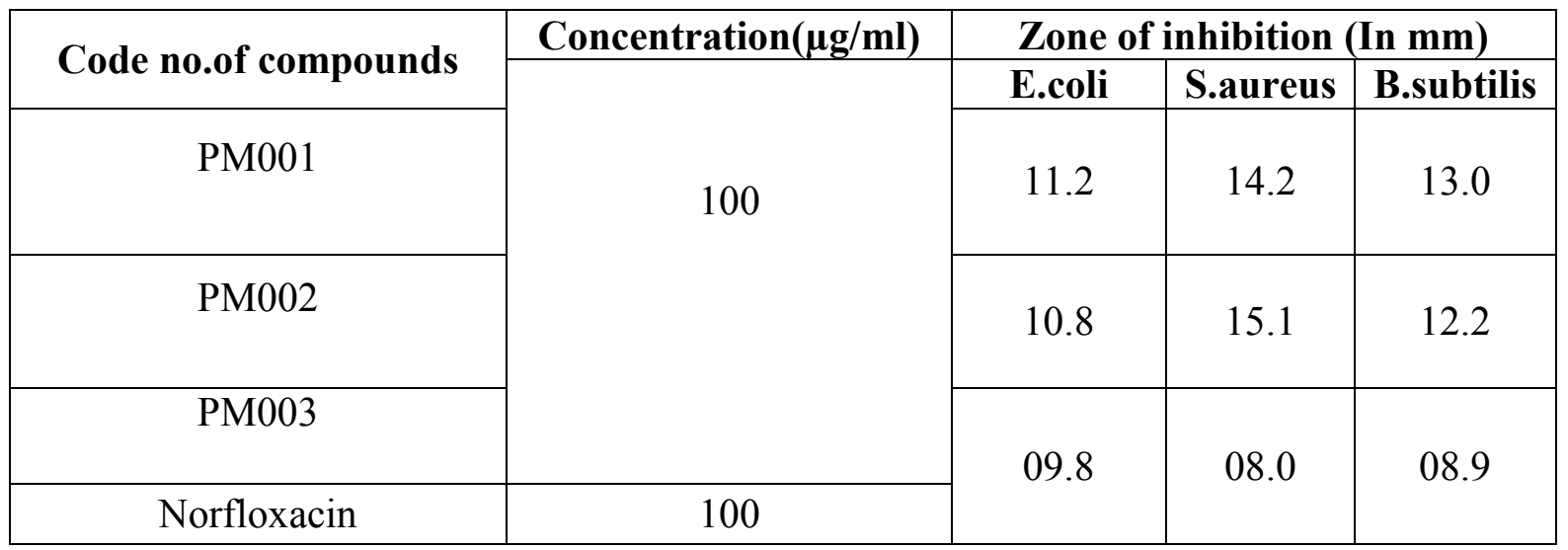

\subsection{IR spectra}

The infra red spectra of carboxylic acid derivative PM001 and its ester derivatives PM002 and PM003 were compared. The aromatic C-H stretching was assigned at $3035-3090 \mathrm{~cm}^{-1}$ for the derivatives, Aliphatic C-H stretching was assigned at $2840-2940 \mathrm{~cm}^{-1}$. $\mathrm{CO}$ Stretching was assigned at $1680-1710 \mathrm{~cm}^{-1}, \mathrm{C}=\mathrm{C}$ stretching was assigned at $1620-1626$ $\mathrm{cm}^{-1}$, C-C stretching at $550-560 \mathrm{~cm}^{-1}$ were assigned for PM001-PM003 [15,16].

\section{2. ${ }^{1} \mathrm{H}$ NMR Spectra}

The ${ }^{1} \mathrm{H}$ NMR Spectra of the PM001 to PM003 were recorded in DMSO solvent and the assignment are detailed in the table. The signal appeared in the region of $10.25 \mathrm{ppm}$ confirms presence of $\mathrm{COOH}$ as shown in the representative spectra of PM 001. Absence of this signal in all other spectra and generation of new peaks in the region of 3.36 to $3.80 \mathrm{ppm}$, confirms presence of ester in PM002 to PM003. The multiplates in the range of 6.54 to $7.31 \mathrm{ppm}$ were assigned to aromatic protons [13-14]. 


\subsection{Anti-microbial activities}

Antimicrobial activities for all synthesized compounds were carried out by agar diffusion method and the average radius of the zone of inhibition was recorded. Among the other derivatives screened, the observations were made and compared with standard Norfloxacin $(100 \mu \mathrm{g} / \mathrm{ml})$ as shown in Table 3.

All the synthesized derivatives showed antibacterial activity against both gram positive and gram negative bacteria at a concentration of $100 \mu \mathrm{g} / \mathrm{ml}$. Best results in terms of antibacterial activity was shown by compounds PM001, moderate results is shown by PM002 where as PM003 shows poor antibacterial activity.

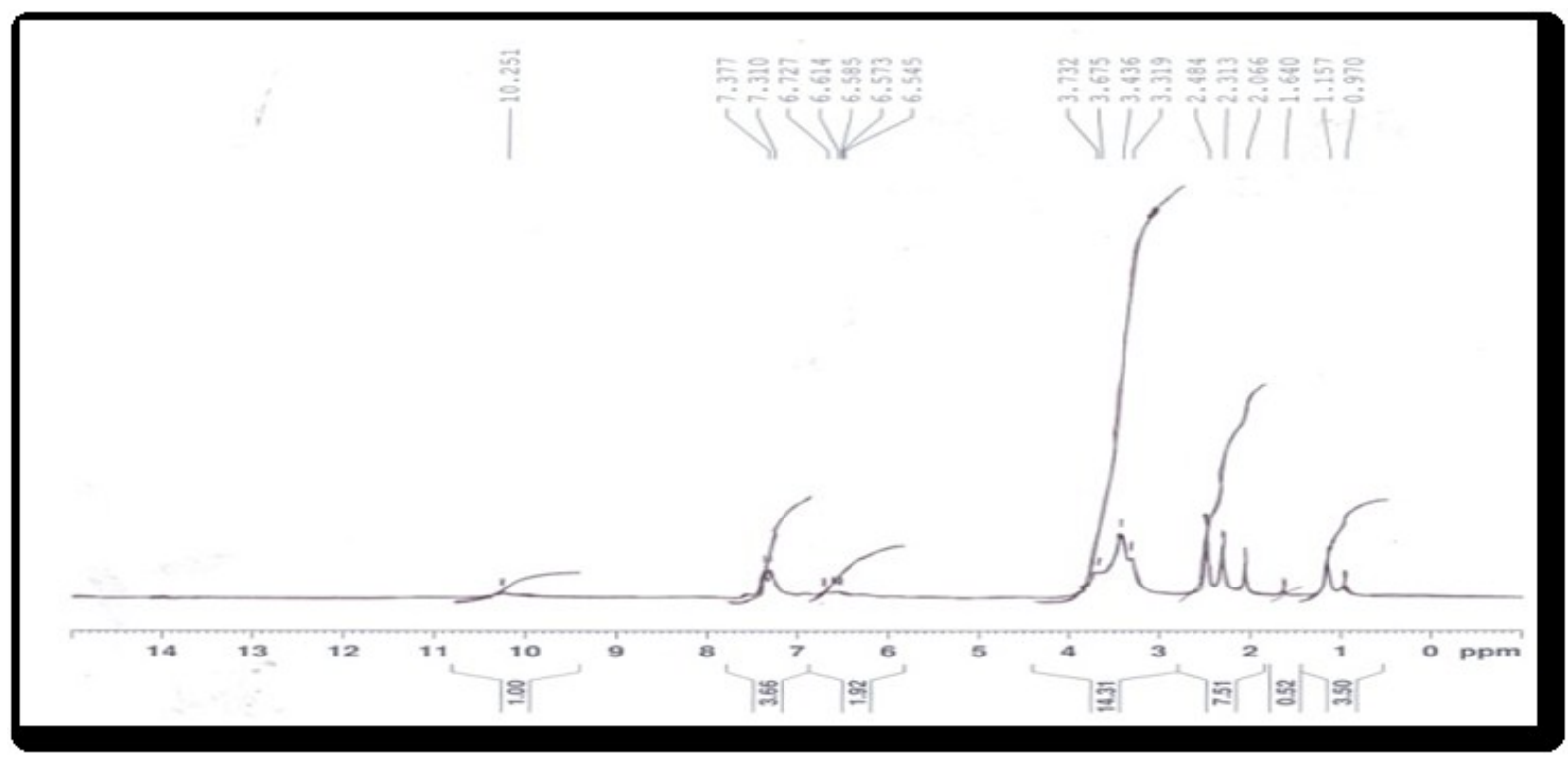

Figure 1. ${ }^{1} \mathrm{H}-\mathrm{NMR}$ Spectra Of The Compound PM001.

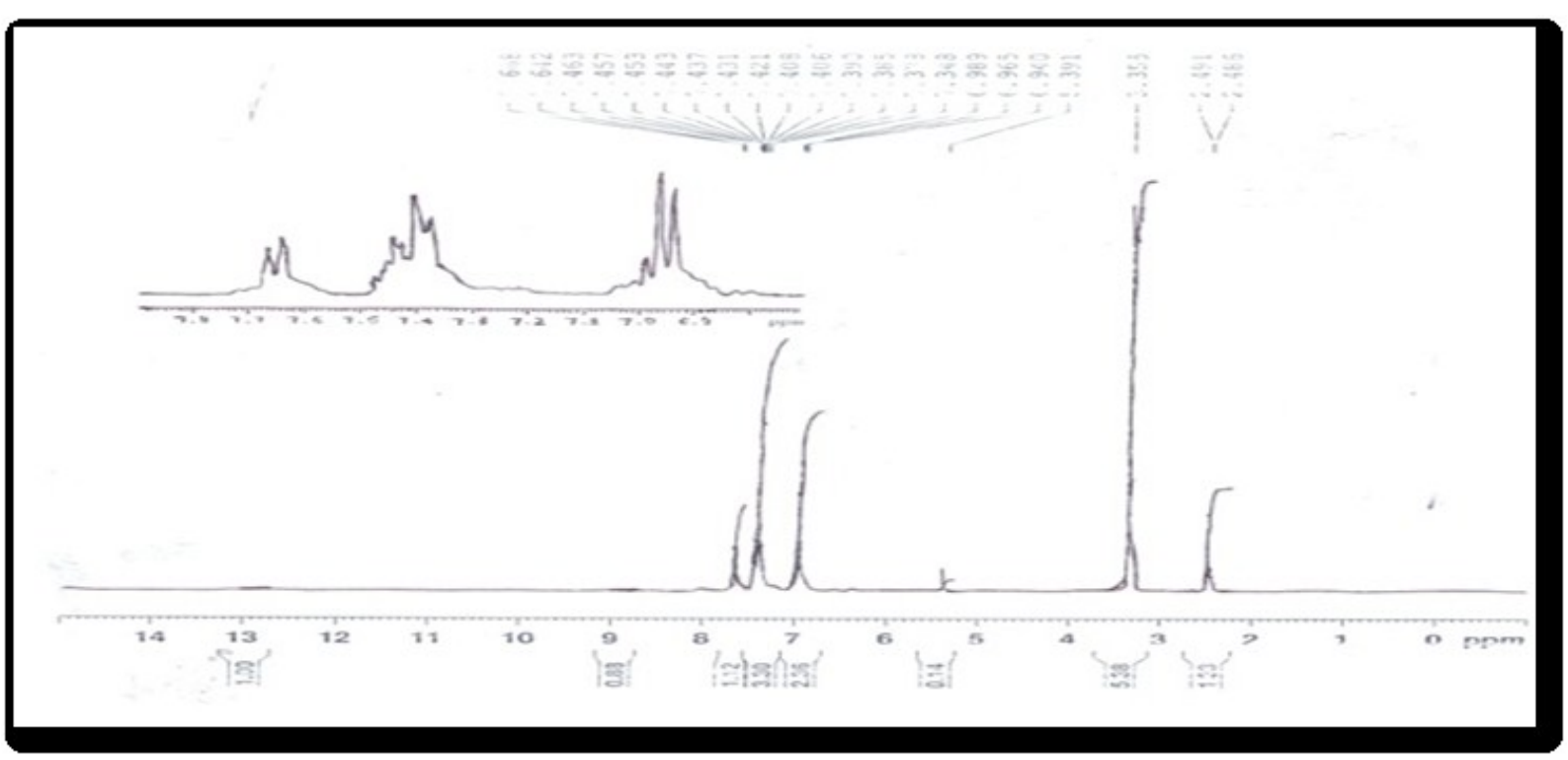

Figure 2. ${ }^{1} \mathrm{H}-\mathrm{NMR}$ Spectra Of The Compound PM002. 


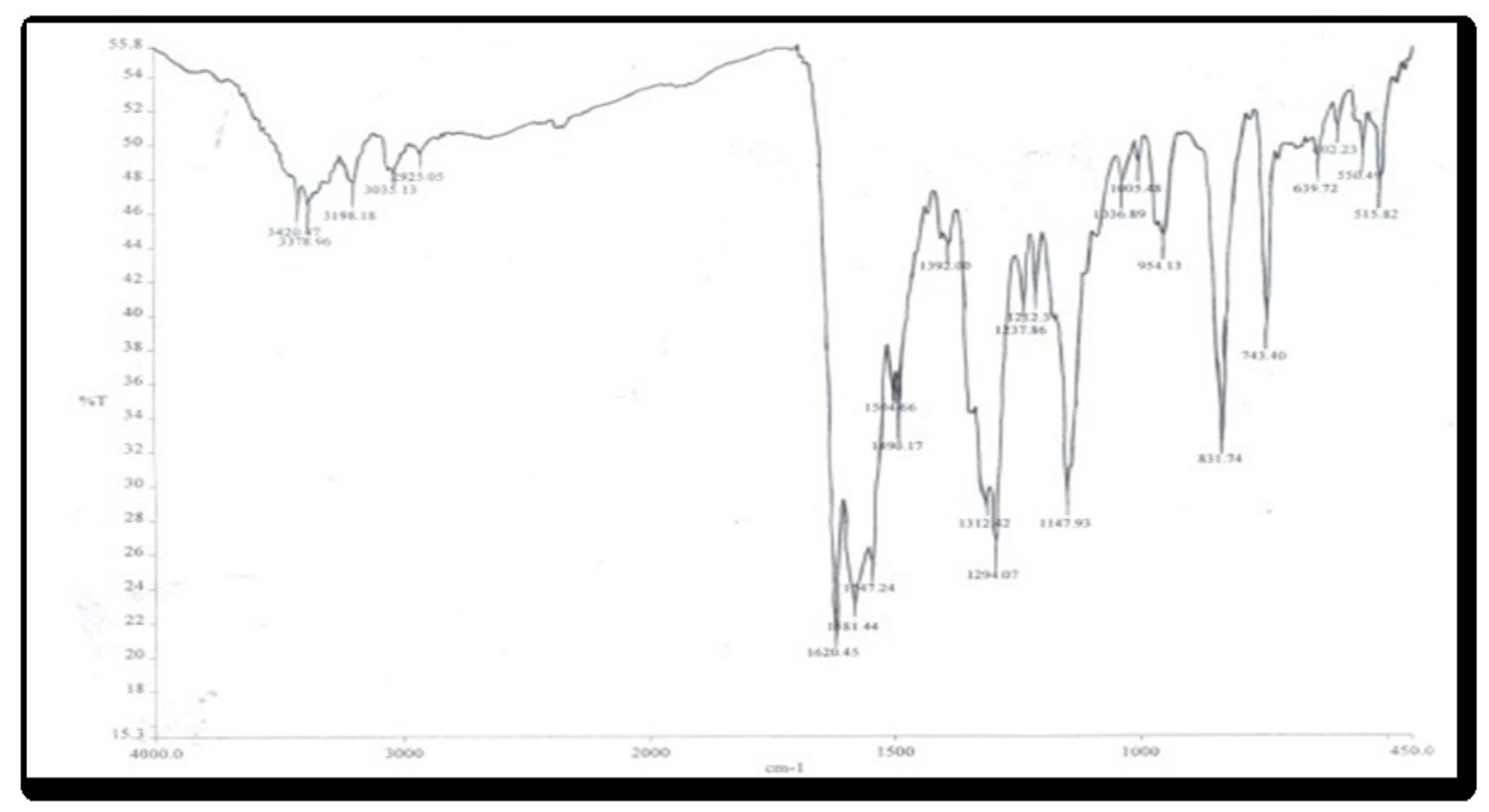

Figure 3. IR Spectra Of The Compound PM001.

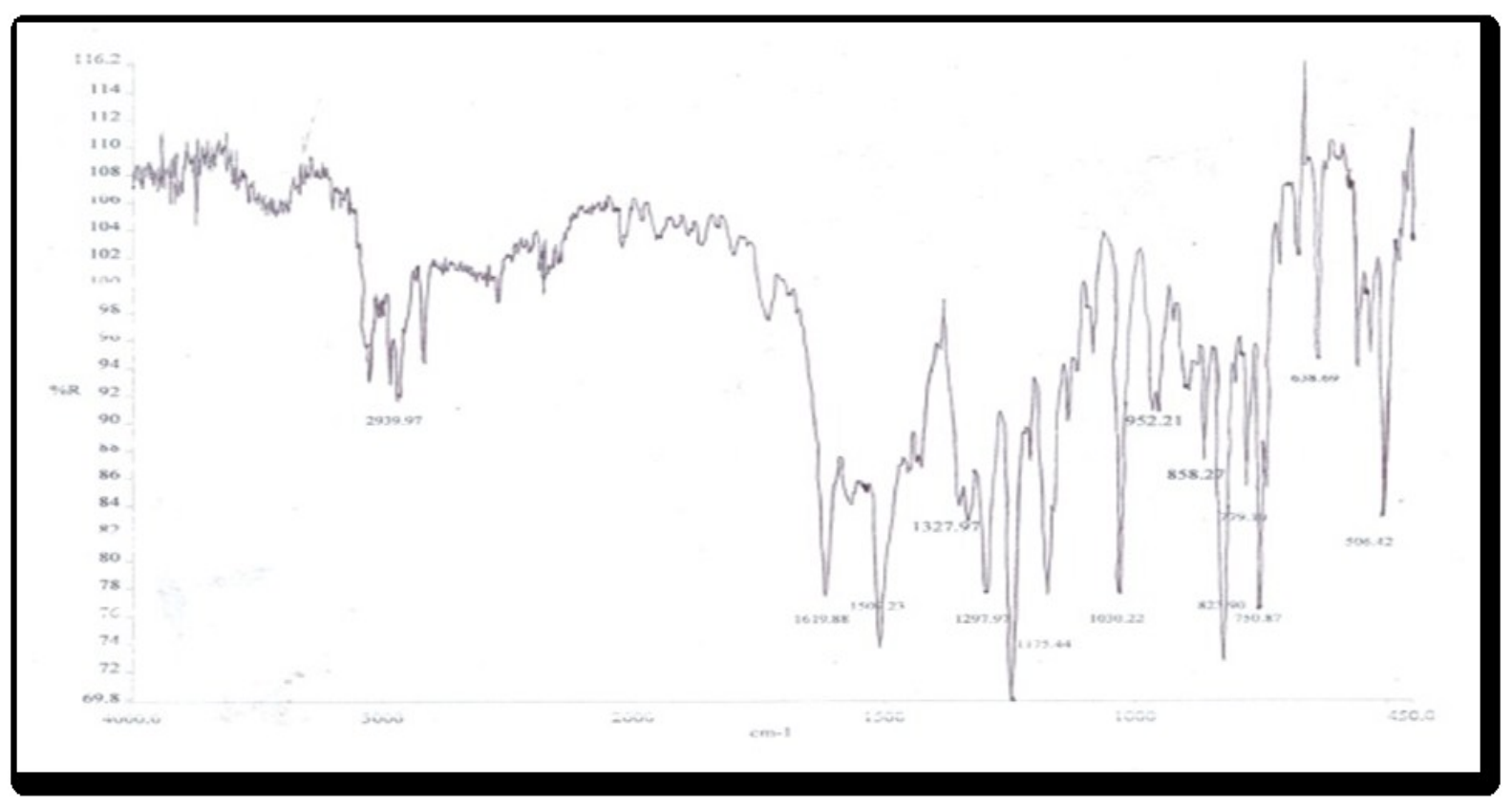

Figure 4. IR Spectra Of The Compound PM002.

\section{CONCLUSION}

Carboxylic acid derivative and its ester derivatives of stilbene have been synthesized in very simple two step process. All the structures are well supported by proton NMR, IR and Elemental analysis. On the basis of above findings following structures are suggested. 


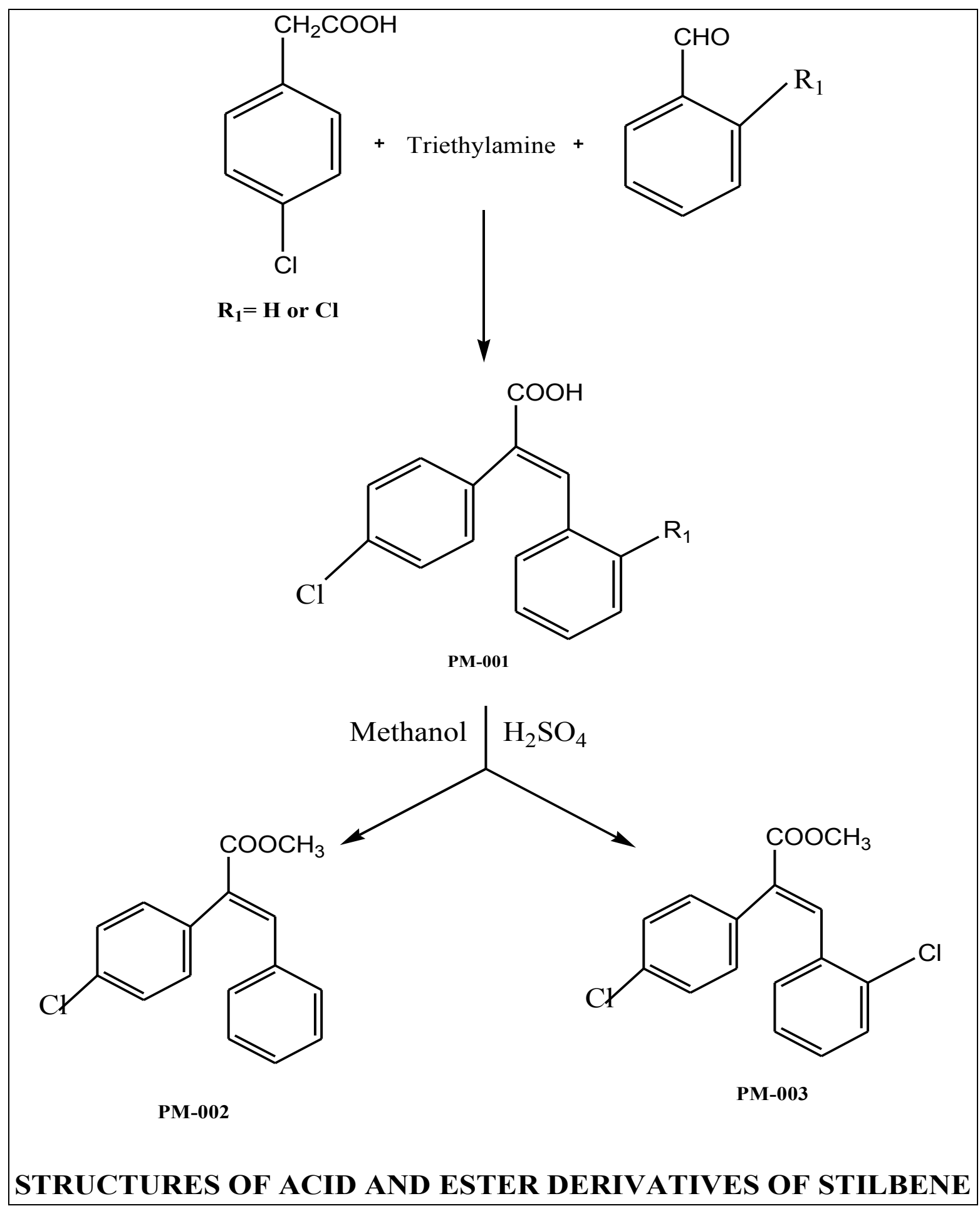

\section{Acknowledgement}

Authors are very thankful to the Management of V.G. Vaze College for the support and encouragement. Also thankful to the Principal Dr. B.B. Sharma and Head Of Chemistry Department Dr.(Ms.) Vandana Panse for laboratory facilities. 


\section{References}

[1] Ioset, J.R.;Marston, A.;Gupta,M.P.;Hostettmann, K.J. Nat.Prod.2001,64,710.

[2] Hu, C.-H.;Ye,S.-J.;Zhao,L.-B.;Wang, J.-L. Chin. Hosp. Pharm.J.2006,7,827.

[3] Shapiro.M.;Argauer,R.J.Econ. Entomol. 1997,90,899.

[4] Argauer, R.;Shapiro, M.J. Econ. Entomol.1997,90,416.

[5] Hu,H.-B.;Jian,Y.F.J Chin. Chem.Soc.2007,54,1189.

[6] Dao-Hang He, Yong-Chuang Zhu, Zhuo-Ru Yang, Ai-Xi Hu, J. Chin. Chem. Soc., Vol.56,No.2, 2009

[7] Grundy, J.(1957) Artificial estrogens, Chem. Rev.,57,281-356,1957

[8] Hughes.G.,M.K. Moore,P.F. and Stebbins, R.B,J.Med.Chem.,7, 511-518, 1964

[9] Ali.H.A,Kondo.K,andTsuda.Y. Chem.Pharm.Bull.40,1130-1136,1992

[10] Matsuda.H,Tomohimo.N,Hiraba.K,HarimaS,K.O.S.Matuso,K.Yoshikawa.M. and Kubo, Biol.Pharm.Bull.,24,264-267, 2001

[11]M.Jang.,L.Cai., Udeani ., K.V.Slowing., C.F.Thomas., C.W.Beecher., H.H.Fong., 1997, Science ; 275 :218-220.

[12]P.Signorelli.,R.Ghidoni, 2005., J.Nutr.Biochem., 16: 446-449.

[13] J.H.HART., 1991, Annuv.Rev.Phytopathol,19:437-458.

[14]Paresh S. More and Santosh G. Singh,International Letters of Chemistry, Physics and Astronomy , 4 (2015) 9-15

[15]B.H.Mehta and P.S.More ,Asian Journal Of Chemistry,vol.19,No.5(2007)4719-4726.

[16]B.H.Mehta and P.S.More,Asian Journal Of Chemistry,Vol.19,No.5(2007),3581-3587. 